\title{
La lengua de la promoción turística institucional. Análisis del portal www.spain.info
}

\section{Rosa María Rodríguez Abella ${ }^{\mathrm{i}}$}

Università di Verona (Italia)

Resumen: En este trabajo nos planteamos, en primer lugar, determinar las características más destacadas del género discursivo portal web. A continuación, a partir de un corpus de estudio constituido por 661 documentos promocionales del portal www.spain.info, nos proponemos identificar, mediante la aplicación de técnicas de análisis tanto cuantitativas como cualitativas, los principales mecanismos lingüísticos utilizados para promocionar el destino España.

Palabras clave: géneros discursivos, lengua del turismo, promoción institucional, lingüística de corpus

Title: The language of the institutional tourism promotion. A study of the web portal www.spain.info

Abstract: The aim of this study is to determine the principal characteristics of the discursive genre of web portal. Moreover, our proposal is to identify the essential linguistic mechanisms used to promote Spain as a tourist destination, through the application of quantitative and qualitative techniques of analysis to a corpus of 661 promotional documents extracted from the web portal www.spain.info.

Keywords: discursive genre, tourism discourse, institutional tourism promotion, corpus linguistics

i E-mail: rosa.rodriguez@univr.it 


\section{Introducción}

Según el Ministerio de Industria, Turismo y Comercio, actualmente en España la industria turística aporta al PIB el 10\% de la riqueza total y representa más del 11\% del empleo ${ }^{1}$. Estos datos, por un lado, reflejan claramente el impacto económico del turismo en nuestro país. Por otro lado, justifican el desarrollo de acciones de marketing por parte del Estado con el fin de promocionar y posicionar el destino España en los principales mercados internacionales emisores.

En el caso español, cabe subrayar, además, que el Estado ha sido pionero en el aprovechamiento de las tecnologías de la información y la comunicación (TIC) para promover la marca España ${ }^{2}$. De hecho, la Administración ha impulsado numerosas acciones de marketing on line en Internet. De entre todas ellas, sin duda, una de las actuaciones más relevantes es la realización del portal turístico www.spain.info ${ }^{3}$, dependiente del Instituto de Turismo de España (Turespaña) ${ }^{4}$; portal, ya en origen, concebido como una herramienta clave para promocionar el país ${ }^{5}$.

En este trabajo nosotros nos planteamos, en primer lugar, determinar las principales características de este género. De hecho, coincidimos con Calvi (2010: 11) cuando señala que:

los planteamientos basados en el concepto de género son los más adecuados para analizar las propiedades de los textos turísticos y su relación con el contexto sociocultural en el que son producidos, permitiendo así integrar la perspectiva lingúístico-formal con los enfoques pragmáticos, discursivos y sociocríticos.

Por consiguiente, trataremos de identificar las convenciones o tipificaciones estructurales y textuales prototípicas del género portal web de promoción turística. En este sentido y de acuerdo con Haas y Grams (citado en Santini 2007: 4), consideramos que: "The Web, with its multimedia capabilities, has also spawned page types that have no equivalent in the print world, such as the home page of a corporation, a page containing audio or video clips, or interactive pages". Por lo tanto, para analizar los géneros digitales es imprescindible tener en cuenta el medio en el que surgen, porque la web como medio les confiere propiedades únicas. Entre las características más destacadas, se pueden citar las siguientes: la interactividad, el papel privilegiado de las imágenes, del sonido y de los vídeos, el acceso rápido y fácil a las informaciones, una perspectiva global, una difusión inmediata y la efectividad.

Asimismo, en el ámbito de los cibergéneros y atendiendo al grado de evolución en que se encuentran, se suelen identificar dos clases de géneros digitales. De hecho, Shepherd y Watters (1998: 3) distinguen entre géneros extant, géneros ya existentes que se han desplazado a la web, y novel, nuevos géneros que nunca existieron en otros medios a excepción de la red. Ateniéndonos a este criterío, el portal web se colocaría bajo la clase novel, puesto que depende completamente del nuevo medio y no de otros géneros preexistentes y su nivel de funcionalidad es muy extenso.

De hecho, los portales web de promoción institucional son considerados ya como uno de los géneros digitales más consolidados y sus características son reconocidas por la comunidad como diferentes con respecto a las de los géneros tradicionales. Por consiguiente, para evidenciar las principales peculiaridades de este cibergénero realizaremos un análisis macro y miscroestructural del portal objeto de estudio.

En segundo lugar, mediante la aplicación de técnicas de análisis tanto cuantitativas como cualitativas, nos proponemos describir la lengua utilizada en este portal para promover los destinos y productos turísticos españoles. Con este objetivo, tras descargar los textos en formato TXT, procederemos, por medio de la herramienta de gestión y explotación de corpus WordSmith Tools 4.0 (en adelante WST4.0), a la extracción de la información lingüística (listado de palabras clave, listados de frecuencia o de referencia, etc.).

Ahora bien, antes de entrar de lleno en el análisis de www.spain.info, creemos que es obligado definir, de manera precisa, el concepto de Publicidad Institucional.

\section{Publicidad Institucional e Internet}

Digamos, para empezar, que, normalmente, bajo la denominación génerica de Publicidad Institucional, solemos aludir al heterogéneo conjunto de campañas realizadas por los diferentes ministerios, organismos y entidades públicas. Es decir, utilizamos esta designación cuando el sujeto que realiza la comunicación es público, esto es, cuando se establece un proceso de comunicación entre las Instituciones Públicas y la Sociedad Civil.

Ahora bien, la Ley 29/2005 de Publicidad y Comunicación Institucional, donde se especifica el régimen jurídico de las campañas institucionales de publicidad y de comunicación promovidas o contratadas por la Administración General del Estado, distingue entre ${ }^{6}$ :

a) Campaña institucional de publicidad, toda actividad orientada y ordenada a la difusión de un mensaje $u$ objetivo común, dirigida a una pluralidad de destinatarios, que utilice un soporte publicitario pagado o cedido y sea promovida o contratada por alguno de los sujetos enunciados en el artículo 1.

b) Campaña institucional de comunicación, la que, utilizando formas de comunicación distintas de las estrictamente publicitarias, sea contratada por alguno de los sujetos enunciados en el artículo 1 para difundir un mensaje u objetivo común a una pluralidad de destinatarios (BOE, 2005: núm.312).

Además, en las disposiciones generales de esta Ley se recoge asimismo que quedan fuera del ámbito de aplicación de la misma las campañas institucionales de carácter comercial, mercantil o industrial y las que son consecuencia de resoluciones y actos administrativos o judiciales ${ }^{7}$. Dicho de otra forma, se establece una neta distinción entre, por un lado, las campañas institucionales de publici- 
dad y comunicación, y, por otro lado, las campañas institucionales comerciales. De ahí que la mayoría de estudios existentes sobre este tema (Cortés González, 2011; Feliu Abadalejo, 2009; García López, 2001) identifique, con mínimas variaciones denominativas, cuatro tipologías de publicidad institucional:

- Publicidad institucional educativo-social: campañas contra el racismo, de prevención del SIDA, etc.

- Publicidad institucional informativa-corporativa: campañas de la Agencia Tributaria, campañas sobre el plazo límite de la Renta, etc.

- Publicidad institucional electoralista-política: campañas para informar a los ciudadanos sobre la existencia de procesos electorales o para fomentar el ejercicio del derecho a voto, etc.

- Publicidad institucional comercial: campañas de Loterias y Apuestas del Estado, Renfe, Turismo de España, etc. ${ }^{8}$

Así pues, se establece una neta división entre campañas que tienen, grosso modo, como fin último el interés general de los ciudadanos - las tres primera tipologías del listado -, y la publicidad comercial - última tipología de la lista -, cuyo objetivo, más o menos declarado, es fundamentalmente mercantilista.

Por otra parte, la Administración General del Estado fija también cada año, a través del Plan de Publicidad y Comunicación Institucional ${ }^{9}$, la cantidad a invertir en comunicación y publicidad institucional ${ }^{10}$.

Aunque, como acabamos de señalar, las campañas institucionales de carácter comercial, mercantil o industrial no entran dentro del ámbito de aplicación de la Ley 29/2005, sin embargo, el Plan sí se hace eco de ellas y, en efecto, proporciona un listado de campañas comerciales, con indicación de los organismos que las promueven y coste de las mismas.

De hecho, se detalla que en 2011 se llevarán a cabo 42 campañas de este tipo - entre las que se halla, por ejemplo, una de Turespaña $-{ }^{11}$, con una inversión total de 141.934.524 euros.

En el Plan de Publicidad y Comunicación Institucional se señalan asimismo los recursos comunicativos que se utilizarán y también la distribución de las herramientas de comunicación. Por ejemplo, en el Plan 2011 se establece que el 61 '1\% de las campañas insertarán anuncios en la prensa escrita y el 49'1\% utilizará internet como soporte publicitario $^{12}$.

Constatamos, por consiguiente, que Internet se erige ya el segundo medio más utilizado para la publicidad y comunicación institucional. El progresivo crecimiento de Internet como soporte publicitario se debe también, obviamente, al continuo incremento del número de usuarios. De hecho, en la última Encuesta de Hábitos Turísticos de los turistas internacionales (HABITUR, 2010: 22) se concluye que, "en 2010, el 44\% de los turistas recibidos en España consultó Internet a la hora de planificar su viaje"13.

Estos datos muestran de forma evidente el notable aumento del uso de este medio como fuente de información en el ámbito turístico. Obviamente, esta tendencia corre paralela al también progresivo afianzamiento de Internet como canal de compra de productos y servicios turísticos ${ }^{14}$. Por todo lo dicho, como coinciden en señalar muchos expertos del sector publicitario, las campañas de publicidad tradicional han ido perdiendo importancia y poco a poco se han ido consolidadando campañas que se basan en nuevas técnicas o formatos de promoción ${ }^{15}$.

En definitiva, a tenor de lo expuesto hasta aquí, resulta evidente la importancia del canal Internet en cualquier tipo de actividad turística. Y, efectivamente, hay que reconocer que, a menudo, las vacaciones de los turistas del siglo XXI comienzan en la web: a través de ella se informan, planifican y compran el viaje. También es frecuente, dado que las experiencias turísticas son para compartirlas, que los propios turistas se conviertan a su vez en nuevos proveedores de contenidos: YouTube, Facebook, blogs, forums, chats, etc., alimentando así este medio con sus propias vivencias ${ }^{16}$.

\section{Análisis del portal www.spain.info}

Como se recoge en el sitio web de SEGITUR ${ }^{17}$, el portal oficial de turismo español, www.spain.info, es uno de los soportes del nuevo Sistema Turístico Español de Promoción online, que se enmarca dentro del Plan del Turismo Español Horizonte 2020, y que permitirá dar respuesta a las necesidades del turista en un entorno de web $2.0^{18}$.

En efecto, en el caso que nos ocupa, esto se refleja en un portal web inteligente y dinámico, capaz de adaptarse a las diferentes tipologías de internautas mostrándole la información que más se ajuste a sus necesidades. El portal, que es propiedad de Turespaña, cuenta con más de 400.000 páginas distintas de contenido, y se propone, como objetivo prioritario, aprovechar las nuevas tecnologías para la información, promoción y comercialización turística de nuestro país.

En cuanto al nombre de dominio, de todos es sabido que, por convención, los nombres suelen estar fomados por dos o más palabras separadas por un punto. La primera palabra suele corresponder a un nombre, en este caso se ha optado por el término inglés spain ${ }^{19}$, que denota claramente la vocación internacional del portal, el deseo de acceder a una "audiencia global". Además, el vocablo elegido coincide exactamente con la marca que se quiere promocionar (España).

Mientras que, normalmente, la segunda palabra sirve para indicar la actividad o procedencia territorial. En nuestro caso se ha elegido el dominio genérico info, probablemente, para señalar que se trata de un proveedor de servicios de información.

En consecuencia, spain.info se convierte en la marca distintiva del turismo español en el ciberespacio. Cabe señalar también que este dominio presenta una óptima localización, pues muestra un buen posicionamiento en los principales buscadores (Google, Yahoo, etc.).

Se ha de tener en cuenta, además, que, dentro de la nueva línea de la campaña de promoción internacional de España, el portal se ha proyectado como estrategia online 
con la que se pretende dar apoyo a la campaña promocional 'I need Spain'. Entre otras cosas, se subraya, por ejemplo, que esta estrategía genera "menos coste que la promoción en medios convencionales y es más efectiva”"20.

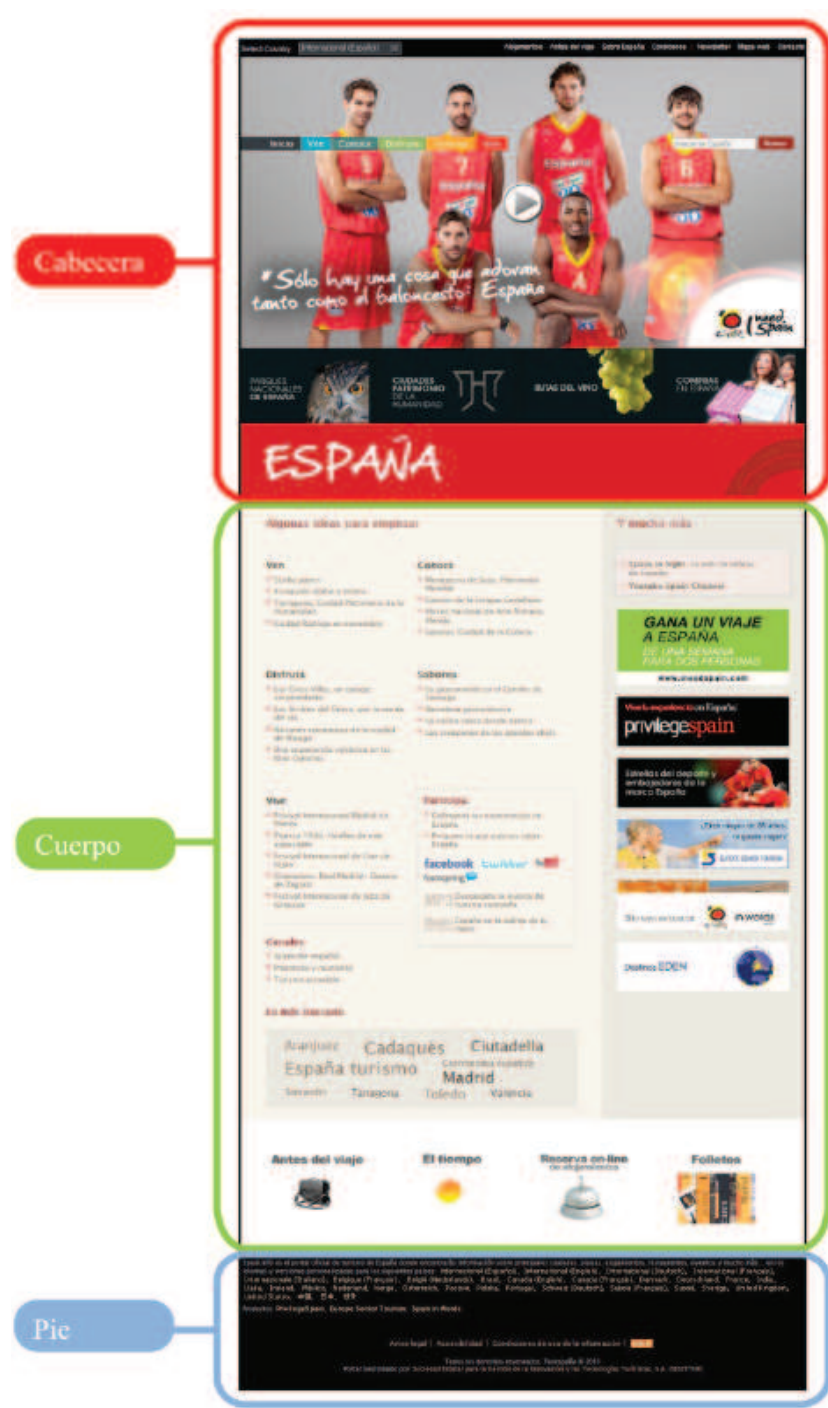

Fig.1 Macroestructura de la página inicial

Pasando ya a la página de inicio del portal, sin duda la más relevante y la más vista, el primer aspecto que llama la atención es que se trata de una página muy larga, de hecho, nos obliga a un movimiento de scrolling.

El tener que correr las páginas determina también la disposición de la información. En líneas generales, se sigue el modelo de la pirámide invertida, característico de la escritura de periódicos. Así pues, la información importante aparece al inicio o cabecera, y al final o pie, la menos relevante.

La página principal ha sido descargada el 14/11/2011 y presenta un diseño innovador y atractivo ${ }^{21}$. Sobre un fondo negro, encontramos desglosada la que será, grosso modo, la estructura de las sucesivas páginas del portal: cabecera, cuerpo y pie de página.

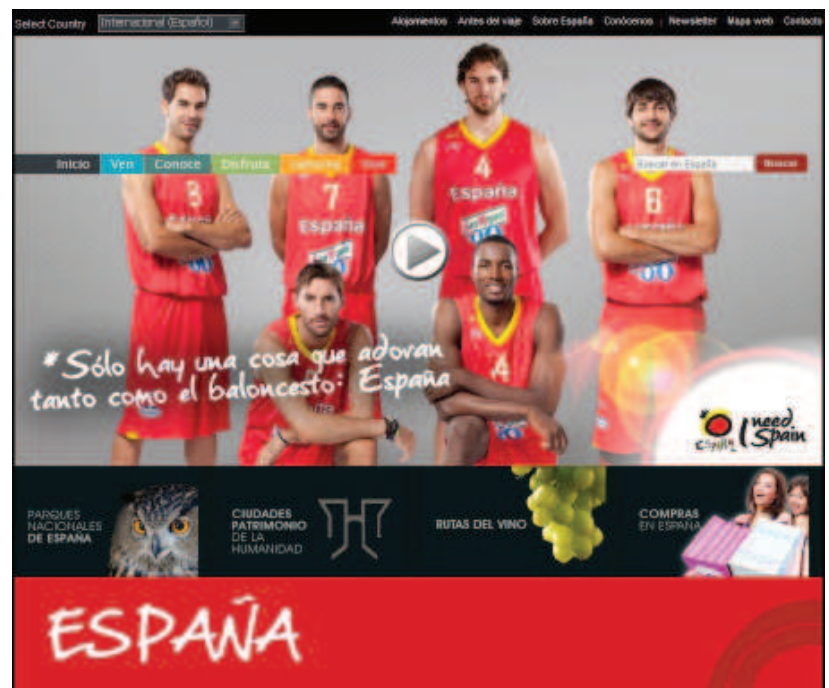

Fig.2 Cabecera de la página inicial

La cabecera, que en este caso ocupa casi una entera pantalla, presenta en la parte superior izquierda un botón de búsqueda que permite seleccionar la lengua y país de origen, facilitando, por consiguiente, la personalización de la información ${ }^{22}$. En la parte superior derecha, una barra de navegación con siete enlaces: Alojamientos, Antes del viaje, Sobre España, Conócenos, Newsletter, Mapa web y Contacto. A continuación, sobre fondo negro, una imagen de los jugadores de la selección española de baloncesto presenta, a la izquierda, un menú de navegación horizontal: Inicio, Ven, Conoce, Disfruta, Saborea, Vive. A la derecha, un buscador interno. Los elementos que acabamos de reseñar: botón de búsqueda, barra de navegación, menú horizontal y buscador interno, constituyen una serie de recursos fijos, presentes en todas las cabeceras de las páginas del portal.

Prosiguiendo con la página de inicio, en la foto de la cabecera, donde los jugadores visten la clásica camiseta roja de la selección española, hallamos, en la parte inferior izquierda de la imagen, el epígrafe: Solo hay una cosa que adoran tanto como el baloncesto: España.

Por último, en la parte inferior derecha de la foto, el logotipo de Miró, introducido por primera vez en la campaña de 1984 como sello del turismo español ${ }^{23}$. Al lado del logotipo, hallamos el nuevo eslogan, I need Spain. Por lo que se refiere al nuevo eslogan, aparte de tratarse de una fórmula concisa, fácil de retener y de repetir ${ }^{24}$, se ha buscado también conectar con la afectividad del receptor.

De hecho, el uso de elementos audiovisuales en la cabecera de la página hace que el mensaje promocional sea más atractivo. Además, vistos los éxitos deportivos obtenidos por los jugadores de la selección, estos se convierten 
en personajes con mucho gancho, capaces, por consiguiente, de generar una cierta empatía con el usuario ${ }^{25}$. Se trata de mostrar que España engancha, o dicho de otra manera: I need Spain.

Debajo de la foto de la selección un nuevo bloque informativo compuesto por cuatro banners promocionales: Parques Nacionales de España, Ciudades Patrimonio de la Humanidad, Rutas del Vino y Compras en España. La cabecera se erige pues en cuadro sinóptico de lo que se puede encontrar en el portal. A continuación, una franja roja con la leyenda España en blanco precede al cuerpo de la página.

El cuerpo presenta tres zonas, gráfica y visualmente, bien diferenciadas: dos verticales y una horizontal.

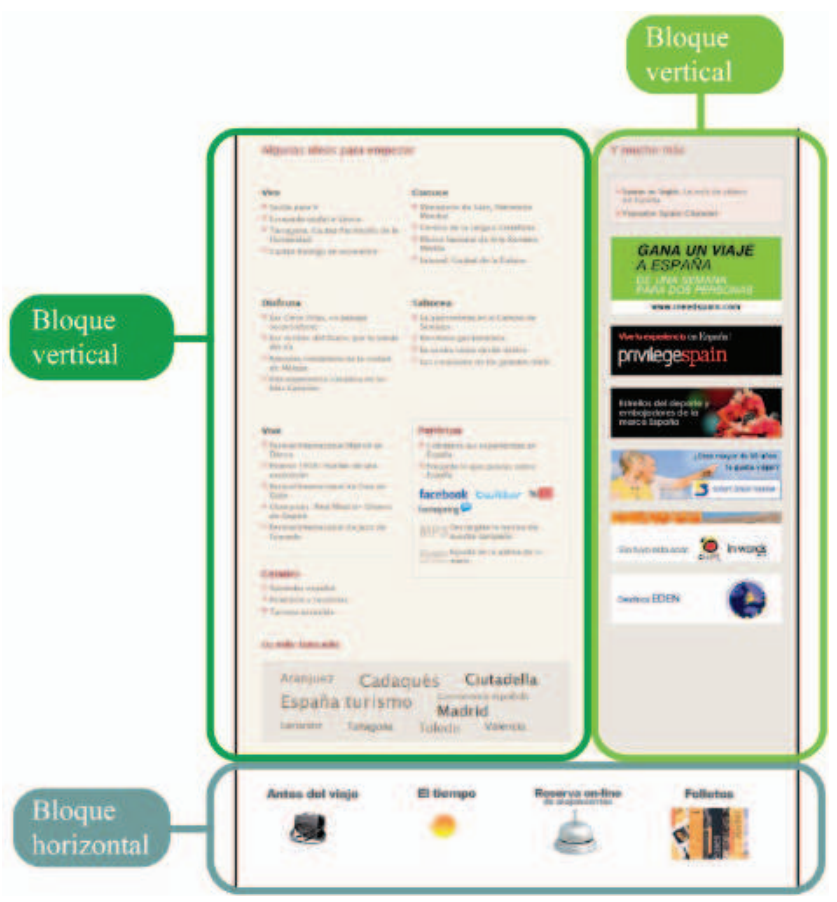

Fig.3 Cuerpo de la página inicial

El primer bloque vertical está constituido por dos columnas verticales, más una horizontal. La verticales se agrupan bajo los rótulos: Algunas ideas para empezar, Canales y Participa, y la horizontal lleva por título: Lo más buscado. Bajo el primer rótulo, Algunas ideas para empezar, se desglosan algunas propuestas de los enlaces: Ven, Conoce, Descubre, Saborea, Vive, ya presentes en el menú de navegación horizontal de la cabecera. En el segundo rótulo, Canales, se agrupan tres tipologías diferentes de turistas. Los que visitan España con el objetivo de aprender la lengua: Aprender español. Los que viajan por motivos de trabajo: Incentivos y reuniones. Y, el último enlace, Turismo accesible, permite a las personas con discapacidad conocer los monumentos, museos, restaurantes, etc. accesibles. En el tercer rótulo, Participa, encontramos una serie de herramientas de carácter interactivo que permiten que los usuarios puedan compartir contenidos en redes sociales como Facebook, Youtube, Twitter, etc.

El segundo bloque vertical consta de una sola columna, donde hallamos un rótulo - Y mucho más, que presenta dos enlaces: Spain in Sight y Youtube Spain Channel - y seis banners promocionales que nos enlazan con: www. ineedspain.com, Privilege Spain, Estrellas del deporte y embajadores de la marca España, Europe Senior Tourism, Spain in Words y Destinos EDEN ${ }^{26}$.

El bloque horizontal en la parte inferior del cuerpo presenta cuatro enlaces: Antes del viaje $e^{27}$, El tiempo, Reserva on-line de alojamientos y Folletos. La disposición de este bloque horizontal se mantiene en todas las páginas del portal.

Por último, el pie de página, donde con letra más pequeña se enumera, brevemente, la información que se puede encontrar en el portal, los idiomas y las versiones personalizadas disponibles.

Desde el punto de vista del diseño, la página es estéticamente agradable. Constatamos también un uso eficaz de los colores para dividir los diferentes bloques de la página de inicio. Destaca el uso del color negro y rojo. El negro preferentemente para el fondo de la página y el rojo como color dominante en la cabecera y para el rotulado. Más allá de la simbología que cada cultura pueda atribuir a estos dos colores (el rojo se suele asociar con las pasiones, la alegría, la vida, etc. y el negro, por ejemplo, con el luto), en este caso, el rojo, color primario, remite obviamente a la bandera nacional española, pero también es uno de los tres colores junto con el negro y el amarillo presentes en el logotipo de Miró.

Comprobamos que tanto en la página de inicio como en las demás páginas del portal se utiliza una jerarquía visual para expresar las relaciones entre los diferentes elementos de la misma. Además, el sistema de navegación es sencillo e intuitivo, presenta información relevante de manera rápida y clara, lo que permite que el turista pueda planificar a través del web todos los aspectos de sus vacaciones.

\section{Análisis lingüístico ${ }^{28}$}

Nuestro corpus de estudio está constituido por 661 documentos promocionales del portal www.spain.info que nos han sido facilitados directamente por Turespaña ${ }^{29}$. Los textos contienen, fundamentalmente, propuestas de viajes y pertenecen a los enlaces: Ven, Conoce, Disfruta y Saborea ${ }^{30}$.

\begin{tabular}{|c|c|c|c|}
\hline $\begin{array}{c}\text { Fuente de } \\
\text { los textos }\end{array}$ & $\begin{array}{c}N^{\circ} \text { de } \\
\text { palabras } \\
\text { (tokens) }\end{array}$ & Types & $\begin{array}{c}\text { TTR } \\
\text { type/token } \\
\text { ratio }\end{array}$ \\
\hline $\begin{array}{c}\text { www. } \\
\text { spain.info }\end{array}$ & 326.867 & 19.032 & 6 \\
\hline
\end{tabular}


Para llevar a cabo nuestro estudio, y a fin de evitar la presencia de unidades léxicas sin contenido específico, en primer lugar, hemos alimentado el programa WST con una lista de exclusión (stopword list) ${ }^{31}$. A continuación, hemos generado un listado por frecuencia de palabras monoléxicas mediante la herramienta WordList.

Por último, con el objetivo de obtener una indicación más fiel con respecto a la frecuencia y, al mismo tiempo, una lista de tamaño más reducido, hemos lematizado la lista de frecuencia obtenida con WST (Figura 1$)^{32}$.

\begin{tabular}{|c|c|c|}
\hline Word & Freq. & Lemmas \\
\hline ESPAÑA & 1535 & \\
\hline CIUDAD & 1042 & ciudad[777] ciudades[265]] \\
\hline ZONA & 653 & zona[475] zonas[178] \\
\hline PARQUE & 650 & parque[501] parques[149] \\
\hline NATURAL & 588 & natural[362] naturales[226]] \\
\hline RUTA & 564 & ruta[302] rutas[262] \\
\hline MUSEO & 563 & museo[449] museos[114] \\
\hline DISFRUTAR & 545 & \\
\hline AÑO & 536 & aก̃o[356] años[180] \\
\hline KILÓMETRO & 503 & kilómetro[6] kilómetros[497] \\
\hline MAR & 491 & $\operatorname{mar}[479]$ mares[12]] \\
\hline CENTRO & 473 & centro[317] centros[156] \\
\hline $\mathrm{TE}$ & 469 & \\
\hline ISLA & 465 & isla[226] islas[239] \\
\hline ENCONTRARÁ & 454 & encontrará[328] encontrarás[126] \\
\hline DÍA & 442 & día[259] días[183] \\
\hline PLAYA & 436 & playa[171] playas[265] \\
\hline ARTE & 425 & arte[368] artes[57] \\
\hline MUNDO & 423 & mundo[420] mundos[3] \\
\hline PATRIMONIO & 409 & patrimonio[407] patrimonios[2] \\
\hline VISITA & 405 & visita[267] visitas[138] \\
\hline AGUA & 401 & agua[190] aguas[211] \\
\hline COSTA & 400 & $\operatorname{costa}[364] \operatorname{costas}[36]$ \\
\hline SIGLO & 391 & siglo[269] siglos[122] \\
\hline DEPORTE & 386 & deporte[223] deportes[163] \\
\hline PAISAJE & 378 & paisaje[202] paisajes[176] \\
\hline NATURALEZA & 369 & naturaleza[368] naturalezas[1] \\
\hline GOLF & 368 & \\
\hline MADRID & 357 & \\
\hline SAN & 352 & \\
\hline
\end{tabular}

Figura 4. Cabecera de la lista de frecuencia lematizada
Si observamos el listado por frecuencia comprobamos que la palabra que encabeza la lista es el nombre propio España. Este término no solo es el más frecuente en nuestro corpus (1535), sino también el que aparece en mayor número de textos (469).

Como es sabido, los topónimos sirven, sobre todo, para identificar y ubicar lugares en el espacio. De hecho, en nuestro corpus, el topónimo España es utilizado, a menudo, como referente espacial de otros nombres:

(1) [... la hermosa bahía de la ciudad gallega de A Coruña, al noroeste de España ${ }^{33}$.

(2) Elija los cortijos de Andalucía, al sur de España, típicas casas de campo restauradas y convertidas en alojamientos [...].

(3) Aragón se encuentra en el norte de España y es una zona con numerosos manantiales, situados en rincones de ensueño [...].

(4) En el noreste de España se halla Tarragona que destaca por su Circo romano.

(5) Sin embargo, esta región situada al sureste de España también es rica en aguas minero-medicinales por las zonas del interior. (6) Esta región del norte de España es uno de los centros mundiales del arte rupestre.

(7) Si continúa hacia el sur de España, a 300 kilómetros se encontrará con Córdoba.

Además, España es también un término autorreferencial, en el que convergen el nombre de marca asociado a nuestro país y el destino que se está promocionando. Como apuntan Febas Borra (1978) y Rodríguez Aramberri (2011) el mecanismo autorreferente es típico del ámbito turístico; de hecho, se trata de una estructura muy usada para transmitir la percepción que el referente tiene o quiera dar de sí mismo.

En algunas ocasiones, pocas en realidad, la imagen proyectada, normalmente a través de enunciados asertivos (ejemplos 8, 9, 10, 11, $12,13,14$ y 15), coincide con los elementos más definitorios que el imaginario colectivo asocia con España:

(8) España es símbolo de pasión, arte y buena vida. Un país rico en ocio, cultura, [...].

(9) España es diversión, alegría, buen clima $y$, sobre todo, fiesta nocturna.

(10) España es el lugar ideal para pasar unas vacaciones con toda la familia.

(11) España es garantía de sol y de temperaturas cálidas en cualquier época del año.

(12) Descubrir España es descubrir "la cultura del toro", pues casi todas sus ciudades poseen [...].

(13) España es, sin duda, el país donde la dieta mediterránea alcanza su plenitud.

(14) España es el mayor productor mundial de aceite de oliva virgen y su calidad [...].

(15) En todo su conjunto, España es un país 
de gran belleza natural dispuesto para la aven tura. Un paraíso [...].

En cambio, otras veces, sobre todo mediante enunciados asertivos y estructuras argumentativas múltiples, constatamos en nuestro corpus un enriquecimiento notable de la imagen proyectada. De tal forma que España deviene un destino en el que se pueden practicar todo tipo de deportes $(16,17,18$ y 19$)$ y actividades $(20,21,22,23$, $24,25,26,27,28$ у 29$)$ :

(16) España es el país ideal para aprender a esquiar.

(17) $\mathrm{Y}$ es que España es uno de los mejores destinos de Europa para hacer windsurf.

(18) España es el lugar ideal para jugar al golf. A lo largo y ancho de nuestra geografía [...].

(19) España es un gran destino para los seguidores del motociclismo.

(20) En todo su conjunto, España es un país de gran belleza natural dispuesto para la aventura. Un paraíso [...].

(21) Por la calidad de sus instalaciones y la riqueza de sus aguas, España es un destino termal bien conocido en Europa.

(22)España es una referencia mundial en paleontología y ahora, $[\ldots]$.

(23) [...] España es el destino elegido por miles de estudiantes procedentes de todo el mundo [...].

(24) En la actualidad, España es un país de referencia mundial para acudir o celebrar ferias, [...].

(25) España es un destino con mucho que ofrecer en "turismo religioso".

(26) España es uno de los mejores lugares de Europa para disfrutar del avistamiento de aves.

(27) España es uno de los países europeos con más "IBAs" (Áreas importantes para las aves), con 391 zonas protegidas.

(28)España es un destino idóneo para realizar un viaje de incentivos culturales.

(29) España es uno de los principales destinos turisticos de Europa para aquellos que eligen el naturismo como estilo de vida.

Contribuyen también a incrementar el abanico de posibilidades del destino España otras palabras de la lista, entre las más representativas: actividades (257), ruta-s (564), turismo (262), vacaciones (146). Algunos ejemplos son:

(30) [...] zonas de juegos infantiles y la posibilidad de realizar actividades náuticas en familia como paseos en barco, pesca, submarinismo, buceo [...].

(31) Además, a principios de año se vivirá otra apasionante edición de la ruta blanca del Pirineo en trineos empujados por perros.

(32) [...] en los que poder practicar algún deporte de aventura, como el senderismo y el turismo ecuestre.

(33) [...]que acompaña al País Vasco, la hace una buena elección para unas completas vacaciones de golf aconsejables para amantes [...].

Evidentemente, cada unidad presenta su propia combinatoria dando lugar, a menudo, a una serie de combina- ciones ocasionales o unidades terminológicas poliléxicas muy frecuentes en el texto. Este es el caso, por ejemplo, de turismo:

(34) Entre los pueblos que participan en esta iniciativa de turismo rural nocturno están: Santa María de Alameda: está a unos 65 kilómetros [...].

(35) Y es que España está entre los principales destinos mundiales del turismo de reuniones ${ }^{34}$.

(36) Apúntese al turismo fluvial y podrá descubrir cómodamente incluso los lugares menos [...].

(37) España es un destino con mucho que ofrecer en "turismo religioso".

(38) [...] FITUR RESIDENCIAL (salón del turismo residencial y vivienda vacacional).

(39) En España son cada vez más las iniciativas que garantizan un turismo cultural para todos. Rutas adaptadas, servicios [...].

(40) El turismo de cruceros es un fenómeno que crece espectacularmente en España.

(41) [...] también se realizan los salones específicos de FITUR ACTIVO (turismo activo y de aventura).

(42) España está cada vez más preparada en lo referente al turismo accesible, al turismo para todos.

Como se puede apreciar en los ejemplos 30, 32, 34, 38, 39 y 41, abundan también los enunciados que se caracterizan por la asuencia de elementos léxicos valorativos, esto es, la realidad se presenta de manera imparcial y objetiva, muy a menudo, a través de encadenamientos argumentativos. En algunos casos, se trata de estructuras argumentativas que responden al procedimientos tesis + argumentos, es decir, se expone una conclusión y después se demuestra con argumentos. En el siguiente texto se ejemplifica a la perfección este procedimiento:

Sitges es una ciudad abierta y tolerante preparada para que te diviertas. Sus más de cuatro kilómetros de playa son perfectos para pasar el día y su paseo marítimo está lleno de restaurantes y de las tiendas más cool. Por la noche, suena la música más moderna en discotecas donde bailarás hasta altas horas y en las que abunda el ambiente LGBT ${ }^{35}$.

En este ejemplo, vemos que la conclusión explícita de este encadenamiento argumentativo es Sitges es una ciudad abierta y tolerante preparada para que te diviertas. En realidad, lo que se dice después son simplemente argumentos que apoyan esta conclusión. Coincidimos con Fuentes Rodríguez / Alcaide Lara (2002: 81) cuando subrayan que:

la finalidad de esta ordenación en el encadenamiento de los enunciados no es más ni menos que la de resaltar, dar relevancia informativa, a este aspecto que se considera fundamental en el producto. Es, por tanto, una forma más de atraer la atención del receptor.

De hecho, en nuestro corpus, es frecuente que el enunciado presente un razonamiento o conjunto de razona- 
mientos en forma de argumentación. También comprobamos que, a menudo, se produce un deslizamiento desde la argumentación a la descripción. Así, para seducir al navegante se presenta una serie de datos cuidadosamente seleccionados y enumerados unos tras otros, donde las razones de la seducción son los propios datos expuestos ${ }^{36}$. Obsérvense los siguientes ejemplos:

Son muchos los motivos para recorrer la Costa Vasca, la franja litoral del País Vasco: 252 kilómetros bañados por el mar Cantábrico y dominados por la intensidad del azul y el verde. Así, entre montañas, rías, acantilados y parques naturales hay extensas playas de arena fina y dorada, que son escenarios perfectos para practicar el surf, el piragüismo o la vela. También hay pueblos y villas de sabor marinero, caseríos, monumentos y museos... [...]

Un destino perfecto para disfrutar del verano en contacto con la naturaleza. La diversidad ecológica y de paisajes que ofrece esta región, encajonada entre el mar Cantábrico y la cordillera montañosa de los Picos de Europa, hace que las opciones de turismo activo sean de lo más variadas. Senderismo, trekking (travesía de montaña), escalada, espeleología, descenso de barrancos, rutas en bicicleta, a caballo y en quad, piragüismo, montañismo, pesca, actividades de orientación... [...].

En el primer caso, Costa Vasca, se hace hincapié en el paisaje, en la práctica de actividades deportivas y, también, en aspectos culturales para justificar la visita a esta zona de España. En el segundo texto, Asturias, se selecciona un producto turístico específico, el turismo activo, y se enumeran las diferentes posibilidades presentes en esta región para practicar determinadas actividades deportivas. En definitiva, se argumenta describiendo. De hecho, hay unanimidad en aceptar que en ámbito turístico, y a través de variadas estructuras argumentativas ${ }^{37}$, la argumentación se erige en una de las principales estrategias persuasivas para seducir al turista.

En realidad, los tres textos que acabamos de presentar nos sirven también para ejemplificar cómo se crea la imagen turística de España. En los dos últimos textos (Costa Vasca, Asturias), la representación del destino se crea, fundamentalmente, caracterizando el espacio geográfico donde tiene lugar la experiencia turística y enumerando el conjunto de instalaciones y servicios a disposición de los turistas. Esto es, el elemento cognitivo es preponderante en ambos textos. Por el contrario, en el texto de Sitges, destaca el elemento afectivo: Sitges es una ciudad abierta $y$ tolerante [...].

Evidentemente, el carácter intangible y la naturaleza multidimensional del concepto de destino turístico hacen que las evaluaciones afectivas sean también fundamentales a la hora de componer la imagen de un determinado destino turístico.

De hecho, si bien es cierto que tradicionalmente se ha concedido mayor importancia al componente cognitivo de la imagen, actualmente existe ya un consenso generalizado que aboga por un equilibrio o complementaridad de las dimensiones cognitiva y afectiva a la hora de proyectar la imagen de un destino ${ }^{38}$.

Pero, limitándonos ahora a la dimensión cognitiva, si retomamos el listado por frecuencia, comprobamos que, sin lugar a dudas, las palabras que presentan un número mayor de ocurrencias proyectan una imagen que, en nuestra opinión, trata de superar el estereotipo de España como destino del sol y playa. De hecho, según un estudio llevado a cabo en el año 2000, "la imagen genérica de España entre los europeos estaría basada en tres elementos principales: el buen tiempo, el sol y la playa" (Fuentes Luque, 2005: 65).

En cambio, en nuestro corpus, el segundo término más frecuente, después del autorreferencial España, es ciudad, con 1042 ocurrencias. Además, esta palabra muestra una frecuencia muy superior a las otras palabras que la siguen. De hecho los lemas que encontramos a continuación: zona-s (653), parque-s (650), natural-es (588), ruta-s (564), museo-s (563), etc. presentan un número de ocurrencias netamente inferior.

La palabra núcleo ciudad la encontramos, a menudo, en la estructura sustantivo + adjetivo:

(43) ciudad colonial, ciudad fortificada, ciudad amurallada, ciudad oculta, ciudad universitaria, ciudad perfecta, ciudad única, ciudad tolerante, ciudad milenaria, ciudad islámica, ciudad abierta, ciudad mediterránea, etc.

donde el sustantivo funciona como término genérico y el adjetivo sirve para destacar las peculiaridades del lugar. Otras veces, las menos, aparece como nombre propio: (44) Ciudad Real, Ciudad Rodrigo, Ciudad de la Porcelana, Ciudad de las Artes y las Ciencias, Ciudad Patrimonio de la Humanidad, etc.

El núcleo ciudad aparece, también, como término genérico en la estructura formada por constituyentes nominales acompañados de la preposición de (sust. + sust.):

(45) ciudad de Barcelona, ciudad de Huesca, ciudad de

San Cristobal, ciudad de León, etc.

En este último caso (45), ciudad sirve para identificar de manera general la naturaleza de la entidad geográfica denonimada.

En cuanto a los otros términos del listado, comprobamos que los elementos reconducibles al estereotipo de España como destino de sol y playa ocupan posiciones poco relevantes: el primero es el lema mar-es (491 ocurrencias) en la posición número once de nuestra lista, en la catorce, isla-s (465 oc.), a continuación, en la diecisiete, playa-s (436), después, en la veintidós, agua-s (401), costa-s (400) en la veintitrés y, por último, sol que con 161 ocurrencias ocupa la posición número ciento cincuenta.

En nuestra opinión, y como ya señalábamos más arriba, es evidente que se busca ampliar y enriquecer el nivel de conocimiento sobre España. Es más, sobre la base de nuestro listado, constatamos que, si bien no se renuncia completamente a los estereotipos que el imaginario colectivo atribuye al destino España, sí que estos se mar- 
ginalizan notablemente, en beneficio de una imagen más variada y plural de nuestro país. En este sentido, coincidimos con Fuentes Luque (2005: 69) cuando señala que "la imagen proyectada por un destino turístico determinado la originan en buena medida las distintas campañas publicitarias". Así pues, de lo anteriormente expuesto se colige que en esta campaña la imagen proyectada se amplía y enriquece enormememente con repecto a la imagen genérica que de España se tiene en ámbito europeo ${ }^{39}$.

\section{A modo de conclusión}

Como es sabido, y siguiendo a Albadalejo Mayordomo (2005: 4) Internet conforma un espacio comunicativo retórico, pues:

quien elabora un sitio web, una página web, está llevando a cabo un proceso productivo retórico en cuanto a la organización semiótica del objeto significativo que construye: con la inventio obtiene y prepara los contenidos, con la dispositio los estructura, con la elocutio los expresa con todos los medios con los que cuenta y con la actio o pronuntiatio los comunica. Es importante que en una web se preste atención a los contenidos y a la expresión, por lo que la elaboración formal con colores, tipografía, espacios, etc. contribuye a la influencia en el receptor, en llevarle adecuadamente a los contenidos ${ }^{40}$.

Es evidente también que la multimedialidad de la web determina que, en mayor o menor medida, todos los signos - visuales, auditivos, lingüísticos, etc. - contribuyan en la formación de un determinado significado. Esto es, el enunciado final es mucho más rico, pues no se limita al solo significado verbal conceptual de una determinada lengua natural. En el portal objeto de análisis, también la música, los vídeos, las imágenes, etc. participan en la construcción del mensaje. De hecho, por una parte, asistimos a un enriquecimiento espectacular de la dimensión cognitiva mediante, sobre todo, la producción de conocimientos nuevos sobre el destino España. Sin lugar a dudas, las más de 400.000 páginas del portal son buena muestra de ello.

Por otra parte, si nos centramos en la dimensión afectiva, es evidente que Internet ha abierto nuevas posibilidades para el desarrollo de nuevas formas de atraer a los turistas. En nuestro caso concreto, nos referimos a los enlaces del portal rotulados Spain in Sight, Youtube Spain Channel, Facebook, Twitter, etc. que permiten transmitir y compartir una serie de experiencias emocionales de manera más directa.

En efecto, como ya hemos señalado, "en la elección del destino los turistas utilizan dimensiones de percepción tanto cognitivas como afectivas" (San Martín / Rodríguez / Vázquez, 2005: 86). En consecuencia,

[...] los destinos deberán enfatizar en su promoción no solo sus recursos naturales o culturales, entre otros, sino también las emociones o sentimientos que puedan evocar (Ibidem 2005: 86).

En nuestro caso, el correcto equilibrio entre ambas dimensiones - cognitiva y afectiva - se traduce en un portal atractivo y prolífico, que explota también el naciente sexto sentido de los navegantes ${ }^{41}$ :

[...] junto al tacto, el olfato, la vista, el oído, hoy disfrutamos de un sentido adicional, que permite tener experiencia instantáneas y adquirir información en fracciones de segundo gracias a Internet. No tenemos que agotar la lectura de un texto, ni siquiera interrumpirla, para abrir un diccionario, buscar una palabra o localizar un sitio, y ya lo sabemos. La lectura resulta menos vertical de lo que solía, no leemos de principio a fin, de arriba abajo, según aprendimos en la edad de la imprenta, pues los textos se han hecho flexibles, digitalmente flexibles (Gullón, 2010: 20).

En definitiva, en el portal objeto de estudio, asistimos a una perfecta conjunción de signos verbales y no verbales, con el objetivo de informar y, al mismo tiempo, persuadir al usuario para que se decante por este destino.

\section{Bibliografía}

Adam Jean- Michel / Bonhomme, Marc

2000 La argumentación publicitaria: retórica del elogio y de la persuasión. Madrid, Cátedra.

Albaladejo Mayordomo, Tomás

2005 "La comunicación retórica en los sitios web". En Fernando Garrido (coord.), ¿ Hacia qué sociedad del conocimiento?, Actas electrónicas del $2^{\circ}$ Congreso On Line del Observatorio para la Cibersociedad, Barcelona, Generalitat de Catalunya - Diputació de Barcelona.

Antonioli Corigliano, Magda / Baggio, Rodolfo

2002 Internet \& Turismo (Tecnologie per competere). Milán, Egea.

Calvi, Maria Vittoria

2010 "Los géneros discursivos en la lengua del turismo: una propuesta de clasificación". Ibérica, 19.

Cortés Gónzalez, Alfonso

2011 "La publicidad institucional en España. Una década en perspectiva”. Razón y palabra, 75 .

\section{El País}

1993 Libro de estilo. Madrid, Ediciones El País.

Febas Borra, José Luis

1978 "Semiología del lenguaje turístico: Investigación sobre los folletos españoles de turismo". Estudios turisticos, 57-58: 17-204.

Feliu Albadalejo, Ángels

2009 "Los ámbitos de la publicidad institucional”. En Feliu, E. (Ed.), Comunicación. Memoria, historia, modelos (pp. 428-436). Madrid, Edipo.

Fernández, Eduardo

2006 Retórica clásica y publicidad. Logroño, Ediciones Instituto de Estudios Riojanos. 
Fuentes Luque, Adrián

2005 La traducción en el sector turístico. Granada, Editorial Atrio.

Fuentes Rodríguez Catalina / Alcaide Lara Esperanza

2002 Mecanismos lingüísticos de la persuasión. Madrid, Arco/Libros.

Fuentes Rodríguez Catalina / Alcaide Lara Esperanza

2007 La argumentación lingüistica y sus medios de expresión. Madrid, Arco/Libros.

Fumero, Antonio / Roca Genís

2007 Web 2.0. Fundación Orange, Url: http://fundacionorange.es/areas/25_publicaciones/WEB_DEF_COMPLETO.pdf (1/02/2012).

García López, Marcial

2001 Publicidad Institucional: el estado anunciante. Málaga, Universidad de Málaga.

Gullón Palacios, Germán

2010 El sexto sentido: la lectura en la era digital. Vigo, Editorial Academia del Hispanismo.

Jiménez, Miguel Ángel

2008 "Caracterización del género "sitio web corporativo» en español”. En Fernández Sánchez, M. M. / Muñoz Martín, R. (Eds.), Aproximaciones cognitivas al estudio de la traducción y la interpretación (pp. 259-300). Granada, Comares, 259-300.

Labiano, Javier

2004 "Entrevista a Jorge Rubio Navarro, Director de Estrategia y Tecnología de SEGITUR”. Sociedad de la información, Septiembre 2004.

Madrid Cánovas, Sonia

2000 "Palabra e imagen. Problemas semióticos del texto publicitario", Revista de Investigación Lingüistica, Vol 3, 1: 113-155.

Organización Mundial del Turismo

1999 Promoción de Destinos Turísticos en el Ciberespacio, Retos del Marketing Electrónico. Madrid, Consejo Empresarial de la OMT.

Pike, Steven / Ryan, Chris

2004 "Destination Positioning Analysis Through a Comparison of Cognitive, Affective, and Conative Perceptions", Journal of Travel Research, vol. 42, 4: 333-342.

Ministerio de la Presidencia

2011 Plan de Publicidad y Comunicación Institucional 2011. Madrid.

Rodríguez Aramberri, Julio

2011 Turismo de masas y modernidad: un enfoque sociológico. Madrid, Centro de Investigaciones Sociológicas.

Rizzo, Maria Virginia / Bordi Alberto

2009 La comunicazione istituzionale sul web (Alla ricerca del sito perfetto). Milán, Il Sole 24 ore.

San Martín Gutiérrez, Héctor / Rodríguez del Bosque Rodríguez, Ignacio / Vázquez Casielles, Rodolfo

2005 "Análisis de la imagen en turismo mediante técnicas estructuradas y no estructuradas: implicaciones competitivas para los detinos turísticos". RAE: Revista Asturiana de Economía, 35: 69-91.

Santini, Marina

2007 "Characterizing Genres of Web Pages: Genre Hy- bridism and Individualization". En Proceeding of the $40^{\text {th }}$ Hawaii International Conference on System Sciences.

Shepherd, Michael / Watters, Charles

1998, "The Evolution of Cybergenres". En Proceedings of the 31 Annual Hawaii International Conference on System Science.

www.ineedspain.com

www.mityc.es

www.segittur.es

www.spain.info

\section{Notas}

1 Para más información véase el URL: www.mityc.es.

2 De hecho, TourEspaña lanza su primer sitio web (www.tourspain.es) el 1 de enero de 1998.

3 De manera síntetica, y ateniéndonos a la definición lexicográfica que de este lema nos proporciona el diccionario CLAVE (2006:1544), concebimos el portal como una "dirección de Internet en la que se ofrece mayor cantidad de servicios que en un sitio web". Cabe señalar que este término en su acepción técnica (Informática) no aparece recogido en la vigésima segunda edición del DRAE, como tampoco se recoge en su acepción técnica sitio.

4 Organismo de la Administración General del Estado encargado de la promoción exterior de nuestro país como destino turístico.

5 El portal www.spain.info fue lanzado en junio de 2002. Sobre los proyectos tecnológicos de la Administración turística española, véase la entrevista a Jorge Rubio Navarro, Director de Estratégia y Tecnología de SEGITUR (2004: 25-27).

6 Como veremos a continuación, la publicidad comercial del Estado no se contempla en esta Ley.

7 Véase el artículo 1 de las disposiciones generales de la Ley 29/2005.

8 Para un desglose detallado de estas cuatro tipologías véase Feliu Abadalejo (2009: 429-435).

9 En este informe se incluyen todas las campañas institucionales que prevee desarrollar la Administración General del Estado y las demás entidades integrantes del sector público estatal. En el Plan se precisa además el objetivo, coste previsible, período de ejecución, herramientas de comunicación utilizadas, sentido de los mensajes, destinatarios, organismos y entidades afectadas.

10 En el Plan 2011 se indica que: "la Administración General del Estado llevará a cabo durante el año 2011 un total de 108 campañas de publicidad o iniciativas de comunicación institucionales, con un coste total previsto de 80.468 .390 euros" 
(Plan 2011: 7).

11 Se trata de la campaña I Need Spain, con un coste de euros 41.900.000 (Plan 2011: 23).

12 En concreto, en el Plan (2011: 13) se especifica que: "El 61'1 $\%$ de las campañas insertarán anuncios en la prensa escrita (incluye dominicales y suplementos), el 49'1\% utilizará internet como soporte publicitario, radio el 40 ' $7 \%$ y televisión el $26^{\prime} 9 \%$. El $23^{\prime} 1 \%$ de las campañas propone los soportes exteriores como medio publicitario, mientras que el $19^{\prime} 4 \%$ hará uso de las revistas y el $12 \%$ de las relaciones públicas. Además el 6'5\% utilizará el marketing y el 4'6\% el cine. Herramientas distintas a todas las anteriores (carteles, folletos, etc.) serán utilizadas en el $20{ }^{`} 4 \%$ de las campañas o iniciativas de comunicación".

13 Según el Informe elaborado por el Instituto de Estudios Turísticos (IET), en 2010, "el 44\% de los turistas recibidos en España consultó Internet a la hora de planificar su viaje; un $22 \%$ habló con amigos o algún familiar y un 21\% recurrió a agencias de viajes". Además, "la mayoría de los turistas - el $55 \%$ - utilizó una única fuente de información. Entre los turistas que consultaron más de una fuente, volvió a sobresalir Internet como principal, que aglutinó el 15\% del total". Véase http://www.iet.tourspain.es/.

14 De hecho, Valcarce (2008: 46) subraya que "los productos turísticos son los más vendidos en la Red".

15 Véase al respecto el Estudio InfoAdex de la Inversión Publicitaria en España 2011 en www.infoadex.es.

16 Aunque hoy en día nos parece inconcebible una vida sin Internet, en realidad, el uso masivo de este medio es bastante reciente y cuenta con apenas una década de historia. De hecho, por ejemplo, el lema Internet, aún no se ha incorpotado a la lexicografía académica, se halla solo como Artículo nuevo en el Avance de la vigésima tercera edición (véase el sitio: www.rae.es).

17 Como se subraya en el propio sitio web: "la Sociedad Estatal para la Gestión de la Innovación y las Tecnologías Turísticas [...] nace con el propósito de convertirse en un nexo de unión entre las nuevas tecnologías y el sector turístico. En este sentido, tiene como objetivos apoyar la promoción turística y la comercialización de los productos y servicios mediante el uso de las nuevas tecnologías, haciendo especial hincapié en Internet". Véase www.segittur.es/Proyectos.

18 A esta nueva web se la denomina también web participativa, porque la Web 2.0 facilita el compartir información, la interoperabilidad, el diseño centrado en el usuario y la colaboración en la World Wide Web; para más información véase Fumero / Genís Roca (2007).

19 Es, a todas luces, evidente la importancia del inglés como lingua franca en la comunicación turística.
20 Véase la nota de prensa sobre la nueva campaña de promoción internacional de España en url: www.mityc.es/es-es/ gabineteprensa/notasprensa/documents/npcampanaineedspain040310.pdf.

21 Hemos constatado que, con el paso del tiempo, se cambia la imagen de fondo de la cabecera y también los banners promocionales presentes en la misma. De hecho, la imagen de la cabecera, hasta la fecha, ya se ha cambiado dos veces. Sin embargo, se mantiene inalterada el resto de la estructura de la página principal.

22 El portal www.spain.info está disponible en cinco idiomas (español, inglés, francés, alemán e italiano), más otros catorce como, por ejemplo, noruego, danés o sueco.

23 Solo en la página de inicio el logotipo ocupa esta posición, en las demás páginas aparece al final de la cabecera en la esquina inferior izquierda.

24 Para un estudio detallado sobre la retórica de los mensajes publicitarios, véase López Eire (1998: 43).

25 Turespaña ha introducido una herramienta de promoción novedosa: el marketing deportivo, para ello ha suscrito en los tres últimos años convenios con la Real Federación Española de Fútbol, la Federación Española de Baloncesto, la FIBA, Dorna-Moto GP o el Real Madrid.

26 Normalmente los banners ocupan posiciones ya bastantes estandarizadas (final de la página o columnas laterales), en este caso, siguiendo esta tendencia los hallamos debajo de la cabecera y en una columna lateral.

27 Este enlace también aparece en la barra de navegación de la zona superior derecha.

28 Dadas las dimensiones del corpus, el presente artículo representa un primer acercamiento al estudio de la lengua del turismo en el portal www.spain.info. Por tanto, en estas líneas presentaremos solo algunas de las características más destacadas. Nos proponemos profundizar y completar el análisis del corpus en trabajos futuros.

29 Un agradecimiento especial a Gemma Miralles, Gerente de Operaciones de Segittur, por proporcionarme y gestionar personalmente ante Turespaña la autorización de uso del corpus.

30 Debido al enorme número de páginas del portal, hemos decidido circunscribir nuestro estudio a estos cuatro enlaces.

31 El filtro léxico utilizado se puede descargar en la siguiente dirección: http://www.unine.ch/info/clef/.

32 Esto es, hemos agrupado las variantes morfológicas de un mismo lexema. 
33 La pluralidad lingüística de España hace que la normalización y el uso homogéneo de los topónimos se convierta en un tema complejo. Por ejemplo, en el Libro de estilo de El País (1993:

79) se señala que: "los nombres de poblaciones españolas deberán escribirse según la grafía aceptada oficialmente por el correspondiente Gobierno autónomo, que no siempre es la castellana".

34 Esta combinación léxica no parece aún muy estable, pues en nuestro corpus convive con otras tres combinaciones muy similares: turismo de reuniones e incentivos, turismo de congresos e incentivos y turismo congresual.

35 Término que se aplica para referirse a alguien que no es heterosexual.

36 Sobre el argumentar describiendo, véase Adam / Bonhome (2000).

37 Para un análisis detallado de las diferentes estructuras argumentativas, véase Fuentes Rodríguez / Alcaide Lara (2002).

38 Sobre la necesaria complementaridad de ambas dimensiones, véase Pike y Ryan (2004).

39 Para más información, véase Noya (2002).

40 Albadalejo (2005: 4) señala también que, obviamente, la retórica funciona de manera distinta según el género del sitio web de que se trate.

41 Según Gullón (2010: 25), este sexto sentido, que inicialmente ha sido desarrollado sobre todo por los jóvenes aunque actualmente ya ha sido adquirido por el resto de la población, "actúa junto a las combinaciones sensoriales tradicionales, modificando las percepciones individuales". 